\title{
What do we know about membranous obstruction of inferior vena cava, or what do we consider pneumonia?
}

\section{Mario Milun*, 을 Šutalo, Petar Martinčić}

General Hospital “Dr. Tomislav Bardek", Koprivnica, Croatia
KEYWORDS: Budd-Chari syndrome, membranous obstruction of inferior vena cava. CITATION: Cardiol Croat. 2018;13(11-12):449. | https://doi.org/10.15836/ccar2018.449

*ADDRESS FOR CORRESPONDENCE: Mario Milun, Opća bolnica “Dr. Tomislav Bardek", Željka Selingera bb, HR-48000 Koprivnica, Croatia. / Phone: +385-99-332-4368 / E-mail: mariomilunee@gmail.com

ORCID: Ana Šutalo, https://orcid.org/0000-0002-7644-6362

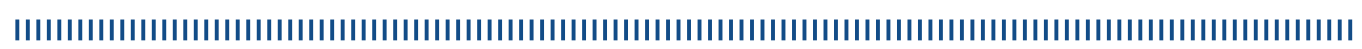

This is a case of a 45-years-old female patient who attended Emergency room (ER) at the Koprivnica General Hospital with a febrile condition, cough, muscular pain, and headache. Laboratory results showed mild anemia, no elevation of leukocytes or CRP. Chest radiogram showed right lobar pneumonia. Medical history showed data of surgical atrial septal defect (ASD) correction in 1980, pulmonary embolism in 2008, and mild right-left shunt diagnosed in 2009. Because there were no signs of leukocytosis or CRP elevation, patient was released home with dual antibiotic therapy. Eight days later patient returned to the ER with almost the same symptoms. Chest radiogram showed stationary findings, again without systemic inflammatory response, so the patient was released home to continue her antibiotics. Day later she was admitted to the Psychiatric ward because of anxiety attack. Lab results and thoracic RTG were stationary, with only worsening of anemia. Broad screening of anemia was done. Tumor markers where normal, so was occult stool hemorrhage test, and gynecology exam. Gynecological ultrasound (UTS) showed enlargement of pelvic veins, and abdominal UTS showed hepatosplenomegaly. Multislice com puted tomography (MSCT) was done, and it showed alveolar infiltration with small pleural effusion, azygos vein was $28 \mathrm{~mm}$ dilation of inferior vena cava (IVC), hepatic and lineal enlargement, and vena porta was $15 \mathrm{~mm}$. So they concluded it was probably chronic right heart failure with right lobar congestion. Transthoracic echocardiography (TTE) was done, and it showed normal systolic left ventricular ejection fraction (LVEF) with mild diastolic dysfunction. In the right atrium (RA) there was a mass on the interatrial septum (IAS) that measured $2.7 \times 1.7 \mathrm{~cm}$. Transoesophageal echocardiography was performed, and its findings confirmed RA "mass" on the IAS, with a left-right shunt near the mass. Differentially there was a possibility of RA myxoma, IVC obstruction, hepatic carcinoma or secondary condition. Patient was sent to University Hospital Centre Zagreb, for further diagnostics. There, MSCT of the abdomen showed no IVC obstruction, or RA mass. Cardiac magnetic resonance imaging (MRI) visualized a 0.3mm thick membranous obstruction of the IVC $2.5 \mathrm{~cm}$ from the RA. Patient was diagnosed with Budd-Chiari syndrome, more precisely membranous obstruction of IVC (MOVC). ${ }^{1-3}$ Percutaneous IVC membrane dilatation was done, with optimal result. Postprocedural TTE showed no RA mass, and RTG showed complete resorption of right basal lung congestion. Patient was discharged home with anticoagulation therapy and is currently under medical monitoring.
RECEIVED:

October 25, 2018

ACCEPTED:

November 5, 2018

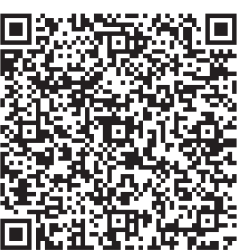

LITERATURE IIIIIIIIIIIIIIIIIIIIIIIIIIIIIIIIIIIIIIIIIIIIIIIIIIIIIIIIIIIIIIIIIIIIIIIIIIIIIIIIIIIIIIIIIIIIIIIIIIIIIIIIII

1. Okuda K, Masayoshi K, Shrestha SM. Proposal of a New Nomenclature for Budd-Chiari Syndrome: Hepatic Vein Thrombosis Versus Thrombosis of the Inferior Vena Cava at Its Hepatic Portion. Hepatology. 1998 Nov;28(5):1191-8. https://doi.org/10.1002/hep.510280505

2. Parker RG. Occlusion of the hepatic veins in man. Medicine (Baltimore). 1959 Dec;38:369-402. PubMed: https://www.ncbi.nlm.nih.gov/pubmed/14430507

3. Hirooka M, Kimura C. Membranous obstruction of the hepatic portion of inferior vena cava. Surgical correction and etiologic study. Arch Surg. 1970 Jun;100(6):656-63. https://doi.org/10.1001/archsurg.1970.01340240024005 